\title{
FACTORS ASSOCIATED WITH MOBILITY APPREHENSION IN AMPUTEES
}

\author{
Shannon L. Mathis*1, \\ ${ }^{1}$ The University of Alabama in Huntsville, USA. \\ *E-mail: shannon.mathis@uah.edu
}

DOI: https://doi.org/10.33137/cpoj.v1i2.32040

\section{INTRODUCTION}

Studies report that after lower-limb amputation, patients have high levels of pain in the form of chronic low back pain, residual limb pain, and phantom pain leading to restrictions in functional activity ${ }^{1}$. Patients with high levels of pain and disability may develop avoidance behaviors. Vlaeyen et al. presents the fear-avoidance model, which suggests that after an injury there are two pathways a patient will take based on their interpretation of acute pain ${ }^{2}$. Pain that is perceived as non-threatening leads to the patient's recovery and return to normal activities of daily life. Pain that is perceived as threatening, or pain catastrophizing, causes anxiety and induces mobility apprehension which leads to avoidance behaviors. Avoidance behaviors may then lead to greater pain, depression, and disability ${ }^{3}$. Factors described in the literature that are related to mobility apprehension were measured in a sample of lower limb amputees. The purpose was to determine which of pain intensity, interference, and catastrophizing lead to increased mobility apprehension.

\section{METHODS}

Subjects: Amputee Coalition Conference attendees were recruited for participation (see Table 1). Apparatus: Subjects completed the Tampa Scale for Kinesiophobia (TSK) to measure mobility apprehension. The Brief Pain Inventory (BPI) measures pain intensity which consists of a patient's current, worst, least, and average pain. The pain interference subscale quantifies general activity, mood, walking ability, normal work, relations with other people, sleep, and enjoyment of life. The Pain Catastrophizing Scale (PCS) measures the tendency to ruminate and magnify pain sensations. Self-report instrument data are presented in Table 2. Data Analysis: Descriptive statistics were explored to present mean and standard deviations for all outcomes. A multivariable linear regression model included all variables of interest and results are presented in Table 3.

\section{RESULTS}

Mobility apprehension was the main variable of interest with a mean score of 34 . This score is approaching the cut-off score of 39 representing a high level. Half of the participants were questioned about recent falls and fear of falls. Of the 31 respondents, $16(52 \%)$ experienced a fall within the last year and $9(29 \%)$ reported a fear of falls.

\section{DISCUSSION}

This data presents an attempt to determine factors associated with mobility apprehension among lower limb amputees. The findings were that pain catastrophizing was directly related to mobility apprehension. Results indicate that a similar trial with a larger sample that is more representative of a wider cross-section of lowerlimb amputees is warranted.

\begin{tabular}{lc}
\hline \multicolumn{2}{l}{ Table 1. Participant Characteristics } \\
\hline Characteristic & n (\%) \\
\hline Mean Age (years, SD) & $48.3(14.8)$ \\
Sex & \\
$\qquad$ Female \\
$\bullet$ Male \\
$\begin{array}{l}\text { Race } \\
\text { • White } \\
\bullet \text { Non-white }\end{array}$ \\
$\begin{array}{l}\text { Mean Years Since Surgery } \\
\text { (SD) }\end{array}$ \\
\hline
\end{tabular}




\begin{tabular}{|c|c|}
\hline Characteristic & M (SD) \\
\hline Mobility Apprehension & $34.2(6.0)$ \\
\hline High, $\geq 39(\mathrm{n}, \%)$ & $10(20 \%)$ \\
\hline Low, <39(n, \%) & $41(80 \%)$ \\
\hline Pain Intensity & $1.6(1.7)$ \\
\hline High, $\geq 5(n, \%)$ & $7(13 \%)$ \\
\hline Low, $<5(\mathrm{n}, \%)$ & $47(87 \%)$ \\
\hline Pain Interference & $2.5(2.6)$ \\
\hline High, $\geq 5(\mathrm{n}, \%)$ & $13(25 \%)$ \\
\hline Low, $<5(\mathrm{n}, \%)$ & $40(75 \%)$ \\
\hline Pain Catastrophizing & $9.1(10.0)$ \\
\hline High, $\geq 24(\mathrm{n}, \%)$ & $4(8 \%)$ \\
\hline Low, < $24(\mathrm{n}, \%)$ & $37(92 \%)$ \\
\hline
\end{tabular}

Table 3. Multivariable regression for factors associated with mobility apprehension

\begin{tabular}{lc}
\hline Characteristic & $\boldsymbol{\beta}(\boldsymbol{p})$ \\
\hline Pain Intensity & $0.25(.48)$ \\
Pain Interference & $-0.03(.96)$ \\
Pain Catastrophizing & $0.31(<.0001)$ \\
\hline
\end{tabular}

\section{CONCLUSION}

Pain catastrophizing was positively associated with mobility apprehension.

\section{SIGNIFICANCE}

Results may assist clinicians by further understanding mobility apprehension and the fear-avoidance model.

\section{REFERENCES}

1. Sinha et al. Influence of adjustments to amputation and artificial limb on quality of life in patients following lower limb amputation. Int J Rehabil Res. 2014, 1;37(1):74-9. DOI: $10.1097 / M R R .0000000000000038$

2. Vlaeyen et al. Fear of movement/(re)injury in chronic low back pain and its relation to behavioral performance. Pain.1995; 62, 363-372. DOI: 10.1016/0304-3959(94)00279$\mathrm{N}$

3. Archer et al. Early postoperative fear of movement predicts pain, disability, and physical health six months after spinal surgery for degenerative conditions. Spine J. 2014;14, 759767. DOI:10.1016/j.spinee.2013.06.087 